\title{
AMENDMENTS
}

\section{Author Correction: Dynamics of social representation in the mouse prefrontal cortex}

Dana Rubi Levy, Tal Tamir, Maya Kaufman, Ana Parabucki, Aharon Weissbrod, Elad Schneidman and Ofer Yizhar (i)

Correction to: Nature Neuroscience https://doi.org/10.1038/s41593-019-0531-z, published online 25 November 2019.

In the version of this article initially published, graphical errors occurred when plotting individual data points: in Fig. 1e, the same data points were accidentally plotted over two adjacent bars; in Extended Data Fig. 5a, dots were switched between adjacent bars. All means and standard errors were plotted correctly, and all data analysis and statistics were done on the correct sets of data. The errors have been corrected in the HTML and PDF versions of the article.

Original:

e

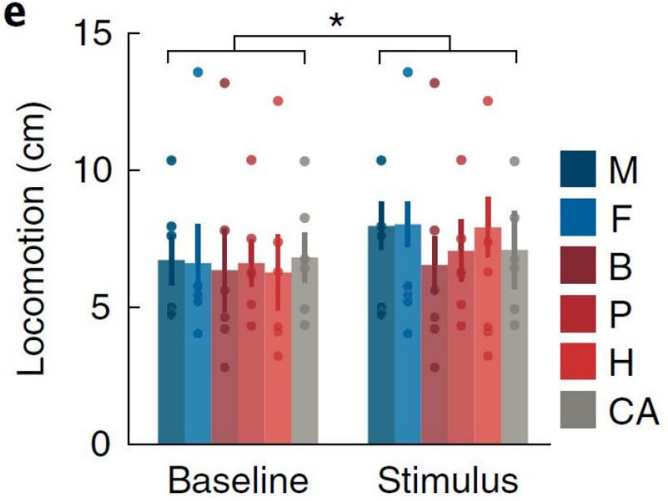

Corrected:

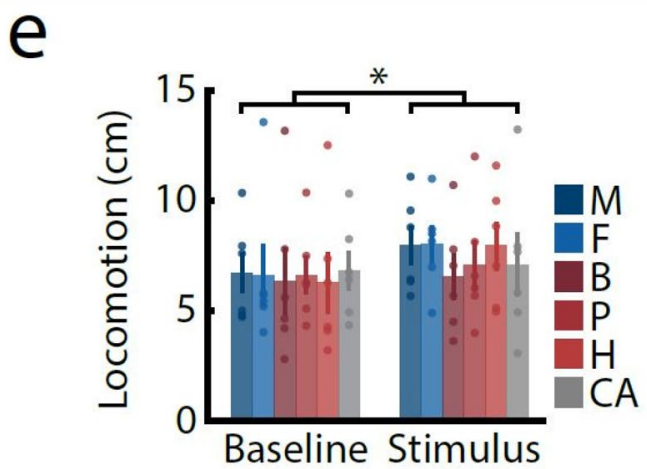

Fig. 3e | Original and Corrected.

Published online: 3 March 2020

https://doi.org/10.1038/s41593-020-0612-z

( $)$ The Author(s), under exclusive licence to Springer Nature America, Inc. 2020

\section{Author Correction: Shifted pallidal co-release of GABA and glutamate in habenula drives cocaine withdrawal and relapse}

Frank J. Meye, Mariano Soiza-Reilly, Tamar Smit, Marco A. Diana, Martin K. Schwarz and Manuel Mameli

Correction to: Nature Neuroscience https://doi.org/10.1038/nn.4334, published online 27 July 2016.

In the version of this article initially published, the first sentence of the fourth paragraph of Methods section "Stereotactic injections" stated, "For VGAT overexpression studies, C57B6J mice were injected in the EPN with rAAV5-Ef1a-DIO-VGAT-mCherry (titer: $1 \times 10^{12} \mathrm{gc} \mathrm{ml}^{-1}$; Addgene catalog \#39320 (ref. 19); viral vector custom-made at UNC Viral vector core, University of North Carolina, USA)." It should have stated, "For VGAT overexpression studies, C57B6J mice were injected in the EPN with a mix of rAAV5-Ef1a-DIO-VGAT (titer: $1 \times 10^{12} \mathrm{gc} \mathrm{ml}^{-1}$; Addgene catalog \#39320 (ref. 19); viral vector custom-made at UNC Viral vector core, University of North Carolina, USA) and rAAV5-EF1a-DIO-mCherry (titer: $7 \times 10^{12} \mathrm{gc} \mathrm{ml}^{-1}$; Addgene catalog \#114471; University of Pennsylvania, USA)."

The error has not been corrected in the original article.

Published online: 5 March 2020

https://doi.org/10.1038/s41593-020-0610-1

(c) The Author(s), under exclusive licence to Springer Nature America, Inc. 2020 